\title{
Mineral Balance and Metabolic Syndrome in Adolescents: Focus on Calcium and Phosphorus Intake
}

\author{
Yoonjin Park ${ }^{1}$ and Jungjin Han ${ }^{2, *(1)}$ \\ 1 Department of Nursing, Joongbu University, Geumsan-gun 32716, Korea; pyj2272@naver.com \\ 2 Department of Nursing, Semyung University, Jecheon-si 27136, Korea \\ * Correspondence: piscesjj.han@gmail.com
}

Citation: Park, Y.; Han, J. Mineral Balance and Metabolic Syndrome in Adolescents: Focus on Calcium and Phosphorus Intake. Healthcare 2021, 9 , 1525. https://doi.org/10.3390/ healthcare 9111525

Academic Editor: Alessandro Sartorio

Received: 8 October 2021

Accepted: 6 November 2021

Published: 9 November 2021

Publisher's Note: MDPI stays neutral with regard to jurisdictional claims in published maps and institutional affiliations.

Copyright: (c) 2021 by the authors. Licensee MDPI, Basel, Switzerland. This article is an open access article distributed under the terms and conditions of the Creative Commons Attribution (CC BY) license (https:// creativecommons.org/licenses/by/ $4.0 /)$.

\begin{abstract}
The incidence of metabolic syndrome, a chronic disease, tends to increase in adolescence, but has not been a high priority in delivery of health services. This study was to investigate the relationship between metabolic syndrome prevalence and mineral balance such as calcium and phosphorus intake among Korean adolescents. This study is a cross-sectional descriptive study using data from the 7th Korean national health and nutrition examination survey (KNHANES) VII-3 (2018) and the 8th KNHANES VII-1 (2019). A total of 895 adolescents aged 12 to 18 who filled in mineral intake questionnaires were analyzed using SPSS. According to their responses, only $2.9 \%$ of the subjects had a calcium: phosphorus intake ratio of 1:1, which is the recommended ratio. Daily phosphorus intake was significantly correlated with systolic blood pressure $(\mathrm{r}=0.448, p<0.001)$, waist circumference $(\mathrm{r}=0.115, p=0.001)$, HDL cholesterol $(\mathrm{r}=-0.113, p=0.002)$, and daily calcium intake $(\mathrm{r}=0.697, p=0.001)$. And, as the serum creatinine increased by 1 , the risk of metabolic syndrome increased 16.5 times (OR: 16.452, 95\% CI: 1.701-159.136, $p<0.05$ ). Excessive phosphorus intake and high creatinine levels may increase the risk of metabolic syndrome in adolescents. Therefore, education is necessary to encourage adolescents to follow a balanced diet that contains essential minerals. In addition, it is suggested to expand the metabolic syndrome prevention education, which has been largely targeted towards adults.
\end{abstract}

Keywords: adolescents; metabolic syndrome; calcium; phosphorus; minerals; nutrients

\section{Introduction}

Metabolic syndrome is a cluster of multiple factors including abdominal obesity, hypertension, abnormal glucose metabolism, dyslipidemia, and low HDL cholesterol. It reportedly increases the risk of cardiovascular disease, diabetes, and cancer [1]. According to the Korea National Health and Nutrition Survey, the prevalence of metabolic syndrome in the last 12 years was $25.5 \%$ among those in their $40 \mathrm{~s}, 17.1 \%$ among those in their 30s, and $7.1 \%$ among those ages 19 to 29 , and that prevalence has been increasing overall [2]. Approximately 3.3\% of children and adolescents worldwide are estimated to have metabolic syndrome [3], suggesting the need for active prevention and management of metabolic syndrome starting with adolescence.

Despite the need for the prevention and management of metabolic syndrome, the Health Behavior and Chronic Disease Statistics released by the Korea Disease Control and Prevention Agency show that only 30\% of adolescents have a balanced diet, and $16.5 \%$ consume fast food, while $35.8 \%$ drink soft drinks at least three times per week [4]. Convenient or instant foods, which are preferred by adolescents, are high in calories, fat, and sodium, while lacking in minerals essential for growth such as calcium, magnesium, and zinc [5]. They must be consumed with caution, as studies report that instant foods such as cup noodles and canned beverages can increase the serum creatinine level in children [6].

Minerals are essential for maintaining homeostasis although they do not provide energy. A daily intake of $100 \mathrm{mg}$ of macrominerals and $20 \mathrm{mg}$ of trace minerals is recommended. Calcium and phosphorus are major macrominerals. Ninety-nine percent of 
calcium exists within the bones and teeth, and $85 \%$ of phosphorus binds with calcium to constitute bones and teeth; thus, the balance between these two minerals is important [7]. Calcium and phosphorus play an important role in cell metabolism, osteogenesis, and protein synthesis [8]. Calcium is involved in the regulation of nerve impulse transmission, muscle contraction, and blood pressure, and phosphorus is involved in maintaining homeostasis and acid-base balance [9].

The guidebook Dietary Reference Intakes for Koreans recommends daily calcium and phosphorus intakes of $800-1000 \mathrm{mg}$ and $1200 \mathrm{mg}$ for adolescents aged 12-18 years, respectively, with a recommended ratio of 1:1 between the two minerals [10]. However, according to the KNHANES, from 2013 to 2017, the median daily intake of calcium was $489.51 \mathrm{mg}$ /day for adolescents aged 12-18 years, lower than the daily recommended amount, and adolescents in the said age range accounted for the highest proportion (male and female: $91.0 \%$ and $90.5 \%$ ) of the total population not meeting the daily requirement [11]. Only $10 \%$ of adolescents took calcium supplements, meaning adolescents get most of their calcium intake from food. The mean daily phosphorus intake was $1261.3 \mathrm{mg} /$ day and $981.1 \mathrm{mg} /$ day for male and female adolescents aged 12-14 years, respectively, and $1306.9 \mathrm{mg} /$ day and $902.7 \mathrm{mg} /$ day for male and female adolescents aged 15-18 years, respectively. Although the phosphorus intake among adolescents was closer to the recommended intake compared to calcium intake, the ratio between calcium and phosphorus intake was not adequate [10]. An unbalanced diet including soft drinks, which are frequently consumed by adolescents, decreases the consumption of healthy foods such as milk, thereby decreasing calcium intakes while excessively increasing phosphorus intakes [12].

Excessive phosphorus intake has a negative effect on bone metabolism by reducing calcium absorption, thereby inducing osteoporosis, and can lead to hyperphosphatemia and hyperparathyroidism [13]. High serum phosphorus levels are a risk factor for vascular calcification [14] and, if present with other risk factors, can increase the risk of and mortality rate from cardiovascular disease $[15,16]$. Calcium intake below the requirement can reduce bone density and mass in growing children, induce osteoporosis, and increase the risk of non-communicable chronic diseases such as hypertension, dyslipidemia, cardiovascular disease, diabetes, and cancer [17-19] For this reason, calcium intake may be closely associated with metabolic syndrome [20,21]. Since metabolic syndrome during adolescence can affect the risk of cardiovascular disease in adulthood, it requires early detection and management [22]. However, due to the relatively low prevalence of metabolic syndrome among adolescents compared to other population groups, adolescents receive low priority in health and medical care services for metabolic syndrome. Furthermore, the diagnostic criteria for metabolic syndrome from the International Diabetes Federation (IDF) and the National Cholesterol Education Program Adult Treatment Panel III (NCEP-ATP III) are interchangeably used to diagnose metabolic syndrome. Despite the reports that inadequate nutrition during adolescence negatively affects chronic diseases such as metabolic syndrome [6], and that metabolic syndrome is an important predictor of renal disease [23], research is still lacking on metabolic syndrome among adolescents.

Thus, in this study we used the data from the 7th KNHANES VII-3 (2018) and the 8th KNHANES VII-1 (2019) to analyze the relation between calcium and phosphorus intakes, creatinine and blood urea nitrogen (BUN), and the prevalence risk of metabolic syndrome in Korean adolescents.

\section{Materials and Methods}

\subsection{Study Design and Participants}

This is a secondary analysis study conducted with the approval to use the raw data. The data from the 7th KNHANES VII-3 (2018) and the 8th KNHANES VII-1 (2019) conducted by the Korea Disease Control and Prevention Agency were downloaded and analyzed in this cross-sectional, descriptive survey study. The KNHANES has been conducted annually since 2007. The survey is conducted through health interviews and mobile exami- 
nations and samples 23 households across 192 regions by probability sampling, surveying approximately 10,000 household members over the period of one year. The KNHANES conducted in 2019 increased the number of surveyed households to 25 and used a systemic sampling method to select participants. The 7th KNHANES VII-3 (2018) surveyed 10,453 participants. Of these, 7992 participants $(76.5 \%)$ had participated in at least one of the following surveys: a health interview, health examination, and/or nutrition survey. The 8th KNHANES VII-1 (2019) surveyed 10,859 participants. Of these, 8110 participants $(74.7 \%)$ had participated in at least one of the three surveys of the KNHANES.

This study aims to analyze the correlation between calcium and phosphorus intake in adolescents and metabolic syndrome. Therefore, 893 adolescents aged 12-18 who reported daily calcium and phosphorus intake were included in the analysis.

\subsection{Methods}

\subsubsection{Data Collection}

General characteristics including age, gender, and the components of metabolic syndrome were investigated. Body mass index (BMI), low-density lipoprotein (LDL), cholesterol, serum creatinine, and serum BUN, which are associated with metabolic syndrome, were also investigated.

\subsubsection{Biochemical Measurements}

A blood test was performed after at least eight hours of fasting. Blood was usually collected from the median cubital vein and cephalic vein. Blood samples were stored in a fridge and analyzed within $24 \mathrm{~h}$ after being transported to the laboratory medicine facility. Fasting glucose, HDL cholesterol, LDL cholesterol, and triglycerides were measured via enzymatic methods using Hitachi automatic analyzer 7600 (Tokyo, Japan).

\subsubsection{Metabolic Syndrome}

Using the definition provided by the NCEP-ATP III [1] in 2001, metabolic syndrome was defined as the presence of at least three of the following factors: (1) increased weight circumference, (2) hypertension, (3) elevated triglycerides, (4) low HDL cholesterol, and (5) impaired fasting glucose. The diagnostic criteria for abdominal obesity in Koreans proposed by the Korean Society for the Study of Obesity [24] were used. Thus, metabolic syndrome was defined as the presence of at least three of the following factors: (1) systolic blood pressure $\geq 130 \mathrm{mmHg}$ or diastolic blood pressure $\geq 85 \mathrm{mmHg}$, (2) a waist circumference $\geq 90 \mathrm{~cm}$ for men and $\geq 85 \mathrm{~cm}$ for women, (3) fasting glucose $\geq 100 \mathrm{mg} / \mathrm{dL}$, (4) blood triglycerides $\geq 150 \mathrm{mg} / \mathrm{dL}$, and (5) blood HDL cholesterol $\leq 40 \mathrm{mg} / \mathrm{dL}$ for men and $\leq 50 \mathrm{mg} / \mathrm{dL}$ for women. For adolescent children, the diagnostic criteria for metabolic syndrome published by the IDF in 2007 were used. For adolescents aged 10-16 years, metabolic syndrome was defined as having a waist circumference $\geq 90 \%$ of the normal waist circumference for adults, blood triglycerides $\geq 150 \mathrm{mg} / \mathrm{dL}$, HDL cholesterol $<50 \mathrm{mg} / \mathrm{dL}$, systolic blood pressure $\geq 130 \mathrm{mmHg}$ or diastolic blood pressure $\geq 85 \mathrm{mmHg}$, fasting blood glucose $\geq 100 \mathrm{mg} / \mathrm{dL}$, or previous diagnosis with type II diabetes. For adolescents aged $\geq 17$ years, the diagnostic criteria for adults were used.

\subsubsection{Phosphorus/Calcium Intake Ratio}

The nutritional survey of the KNHANES consisted of the current status of dietary behavior, dietary supplements, nutritional knowledge, and food stability, and the contents of food intake one day before the survey (24-h recall method), and daily nutrient intake were calculated. The Dietary Reference Intakes for Koreans 2020 [10] recommends calcium intakes of 900-1000 mg/day and 800-900 mg/day for male and female adolescents, respectively, and a phosphorus intake of $1200 \mathrm{mg} /$ day for both genders. In this study, correlations between calcium and phosphorus intakes and metabolic syndrome were analyzed by dividing participants into groups with varying ratios of calcium-to-phosphorus intakes $(1: 1,1: 2,1: 3,1: 4$, and 1:5). 


\subsubsection{Statistical Analysis}

SPSS version 22 (IBM Co., Armonk, NY, USA) was used for data analysis with a significance level of $p$-value $<0.05$. Since regions (enumeration districts) are sampled by stratified multi-stage cluster sampling, which is a complex sampling method, weights were applied to each region using the SPSS Complex Samples module. The weight of the KHNANES is an expanded multiplier given that an estimate represents the entire population of South Korea and is calculated by reflecting the extraction and response rates and the population distribution. If a new variable was produced by combining several variables or a statistical model was constructed using several variables, the survey sections, domains, and items of all variables were considered in order to choose appropriate weights. Weights that encompass several survey sections, domains, and items were named "weights for correlation analysis" and presented for each year.

Differences in the calcium/phosphorus ratio according to general characteristics were analyzed using ANOVA and a t-test. To identify predictive risk factors of metabolic syndrome, the subcategories of metabolic syndrome (waist circumference; high blood pressure; abnormal triglyceride level; abnormal HDL cholesterol; and abnormal fasting glucose level) and phosphorus and calcium intakes were analyzed by binomial regression. Pearson's correlations were used to identify correlations among the factors.

\section{Results}

\subsection{Demographic and Disease Characteristics}

This study included 893 participants, comprising 470 males and 423 females. The mean age of the male and female participants was 14.81 and 14.96 years, respectively. The mean waist circumference was $63.55 \mathrm{~cm}$ for males and $69.08 \mathrm{~cm}$ for females, and the mean BMI was 22.07 for males and 21.08 for females. The mean systolic \& diastolic blood pressure of male and female was $112.36 \mathrm{mmHg}, 68.31 \mathrm{mmHg}$ and $105.62 \mathrm{mmHg}, 67.13 \mathrm{mmHg}$, respectively. Also, the mean of blood sugar was $92.89 \mathrm{mg} / \mathrm{dL}$ for males and $91.21 \mathrm{mg} / \mathrm{dL}$ for females. The mean serum creatinine level was $0.77 \mathrm{mg} / \mathrm{dL}$ for males and $0.62 \mathrm{mg} / \mathrm{dL}$ for females, and the mean BUN level was $13.51 \mathrm{mg} / \mathrm{dL}$ for males and $11.67 \mathrm{mg} / \mathrm{dL}$ for females. The mean calcium intake was $599.86 \mathrm{mg} /$ day for males and $475.37 \mathrm{mg} /$ day for females. The mean phosphorus intake was $1271.34 \mathrm{mg} /$ day for males and $938.41 \mathrm{mg} /$ day for females. Of the respondents, 23 males $(5.9 \%)$ and 20 females $(4.7 \%)$ had metabolic syndrome (Table 1).

Table 1. General Characteristics of Participants $(\mathrm{N}=893)$.

\begin{tabular}{ccc}
\hline Category & \multicolumn{2}{c}{ N (\%) or $\mathbf{M} \pm \mathbf{S D}$} \\
\cline { 2 - 3 } Age & Male (N = 470) & Female (N = 423) \\
\hline Waist circumference (cm) & $14.81 \pm 2.05$ & $14.96 \pm 2.05$ \\
Height (cm) & $63.55 \pm 15.32$ & $69.08 \pm 8.61$ \\
Weight (kg) & $169.05 \pm 8.87$ & $160.02 \pm 6.36$ \\
BMI & $63.55 \pm 15.32$ & $54.11 \pm 11.28$ \\
Blood pressure & $22.07 \pm 4.28$ & $21.08 \pm 3.94$ \\
Systolic (mmHg) & & $105.62 \pm 8.57$ \\
Diastolic (mmHg) & $112.36 \pm 10.32$ & $67.13 \pm 8.52$ \\
Fasting glucose (mg/dL) & $68.31 \pm 9.33$ & $91.21 \pm 7.67$ \\
Serum total cholesterol (mg/dL) & $92.89 \pm 7.38$ & $166.52 \pm 27.20$ \\
HDL cholesterol (mg/dL) & $159.13 \pm 26.79$ & $53.24 \pm 10.35$ \\
Triglyceride (mg/dL) & $49.15 \pm 9.37$ & $89.17 \pm 46.26$ \\
Serum creatinine (mg/dL) & $91.23 \pm 55.78$ & $0.62 \pm 0.09$ \\
Serum BUN (mg/dL) & $0.77 \pm 0.15$ & $11.67 \pm 2.83$ \\
Phosphorus intake (mg/day) & $13.51 \pm 3.20$ & $938.41 \pm 418.75$ \\
Calcium intake (mg/day) & $1271.34 \pm 594.53$ & $475.37 \pm 298.55$ \\
Metabolic syndrome prevalence (\%) & $599.86 \pm 350.80$ & $20(4.7)$ \\
\hline
\end{tabular}




\subsection{Differences in General Variables According to Ratios between Calcium and Phosphorus Intakes}

Participants were divided into groups according to the calcium/phosphate intake ratio $(1: 1,1: 2,1: 3,1: 4$, and 1:5). The mean age of the participants in each group was 15.04, 14.64, $14.98,15.10$, and 15.32 years, respectively. The mean serum creatinine level (in $\mathrm{mg} / \mathrm{dL}$ ) was $0.74 \pm 0.135,0.68 \pm 0.150,0.71 \pm 0.145,0.71 \pm 0.155$, and $0.72 \pm 0.155$, respectively, with significant differences between the groups $(p<0.05)$. The mean daily phosphorus intake (in $\mathrm{mg}$ /day) was $852.08 \pm 487.406,1087.51 \pm 521.773,1133.21 \pm 498.45,1186.24 \pm 659.936$, and $1144.61 \pm 605.653$, respectively. The group with a calcium/phosphorus ratio of 1:4 had the lowest calcium intake, which was significantly lower than the calcium intakes in the other groups $(p<0.05)$ (Table 2$)$.

Table 2. Comparison of General Characteristics among the Calcium/Phosphorus intake ratio $(\mathrm{N}=893)$.

\begin{tabular}{|c|c|c|c|c|c|c|c|}
\hline \multirow{2}{*}{ Category } & \multicolumn{5}{|c|}{ Calcium/Phosphorus Intake Ratio } & \multirow[t]{2}{*}{$\mathrm{F} / \chi^{2}$} & \multirow[t]{2}{*}{$p$} \\
\hline & $\leq 1: 1$ & $\leq 1: 2$ & $\leq \mathbf{1 : 3}$ & $\leq \mathbf{1 : 4}$ & $>1: 5$ & & \\
\hline Age & $15.04 \pm 2.01$ & $14.64 \pm 2.03$ & $14.98 \pm 2.05$ & $15.10 \pm 2.06$ & $15.32 \pm 2.06$ & 2.758 & 0.027 \\
\hline \multicolumn{8}{|l|}{ Gender } \\
\hline Male & 10 & 197 & 155 & 65 & 43 & 1.264 & 0.868 \\
\hline Female & 16 & 196 & 121 & 56 & 34 & & \\
\hline \multicolumn{8}{|l|}{ Waist circumference (cm) } \\
\hline Male & $81.90 \pm 12.47$ & $74.13 \pm 12.15$ & $75.51 \pm 10.21$ & $76.97 \pm 11.96$ & $77.13 \pm 12.68$ & 1.748 & 0.139 \\
\hline Female & $68.02 \pm 6.59$ & $69.53 \pm 8.24$ & $68.82 \pm 9.47$ & $68.58 \pm 8.49$ & $68.68 \pm 8.94$ & 0.250 & 0.910 \\
\hline BMI & $22.75 \pm 5.36$ & $21.43 \pm 4.02$ & $21.60 \pm 4.07$ & $21.64 \pm 4.11$ & $22.03 \pm 4.71$ & 0.785 & 0.535 \\
\hline \multicolumn{8}{|l|}{ Blood pressure } \\
\hline Systolic (mmHg) & $110.61 \pm 11.75$ & $109.32 \pm 10.46$ & $108.55 \pm 9.40$ & $109.98 \pm 10.13$ & $109.09 \pm 10.22$ & 0.543 & 0.704 \\
\hline Diastolic (mmHg) & $70.13 \pm 9.14$ & $67.91 \pm 8.58$ & $67.48 \pm 8.73$ & $67.15 \pm 9.00$ & $68.10 \pm 11.42$ & 0.632 & 0.640 \\
\hline Fasting glucose $(\mathrm{mg} / \mathrm{dL})$ & $90.52 \pm 6.40$ & $92.56 \pm 7.97$ & $92.11 \pm 73.32$ & $90.73 \pm 7.03$ & $92.57 \pm 7.27$ & 1.484 & 0.205 \\
\hline Serum total cholesterol (mg/dL) & $163.81 \pm 29.13$ & $163.56 \pm 28.75$ & $160.41 \pm 25.19$ & $160.15 \pm 25.04$ & $168.60 \pm 28.40$ & 1.531 & 0.191 \\
\hline \multicolumn{8}{|l|}{ HDL cholesterol $(\mathrm{mg} / \mathrm{dL})$} \\
\hline Male & $50.00 \pm 8.36$ & $50.44 \pm 9.28$ & $48.10 \pm 8.92$ & $49.02 \pm 10.22$ & $47.23 \pm 9.78$ & 1.664 & 0.157 \\
\hline Female & $54.93 \pm 13.70$ & $52.83 \pm 10.83$ & $53.07 \pm 9.94$ & $52.06 \pm 8.08$ & $57.43 \pm 10.08$ & 1.469 & 0.211 \\
\hline Triglyceride (mg/dL) & $78.57 \pm 31.79$ & $89.27 \pm 47.10$ & $89.82 \pm 52.57$ & $90.99 \pm 55.12$ & $99.45 \pm 66.61$ & 0.842 & 0.499 \\
\hline Serum creatinine (mg/dL) & $0.74 \pm 0.13$ & $0.68 \pm 0.15$ & $0.71 \pm 0.14$ & $0.71 \pm 0.15$ & $0.72 \pm 0.15$ & 2.472 & $0.043^{*}$ \\
\hline Serum BUN (mg/dL) & $11.48 \pm 3.66$ & $12.41 \pm 3.05$ & $12.96 \pm 3.32$ & $12.66 \pm 3.20$ & $13.16 \pm 2.85$ & 2.221 & 0.065 \\
\hline Phosphorus intake (mg/day) & $852.08 \pm 487.40$ & $1087.51 \pm 521.77$ & $1133.21 \pm 498.45$ & $1186.24 \pm 659.93$ & $1144.61 \pm 605.65$ & 2.442 & $0.045^{*}$ \\
\hline Calcium intake (mg/day) & $928.18 \pm 541.79$ & $694.56 \pm 349.15$ & $458.82 \pm 203.31$ & $343.25 \pm 185.80$ & $233.99 \pm 123.70$ & 83.887 & $<0.001$ * \\
\hline Metabolic syndrome prevalence & 3 & 18 & 15 & 5 & 2 & 4.869 & 0.301 \\
\hline
\end{tabular}

* $p<0.05$; post-hoc Scheffe test was done. No significance was shown between groups.

\subsection{Correlation Analysis}

The correlations between the components of metabolic syndrome-systolic and diastolic blood pressure, waist circumference, fasting glucose, triglycerides, and HDL cholesterol-and daily calcium and phosphorus intakes were analyzed. Daily phosphorus intake was significantly positively correlated with systolic blood pressure $(\mathrm{r}=0.103$, $p<0.004)$, waist circumference $(\mathrm{r}=0.115, p=0.001)$, daily calcium intake $(\mathrm{r}=0.697$, $p<0.001)$ and negatively correlated with HDL cholesterol $(\mathrm{r}=-0.113, p=0.002)$.

Daily calcium intake was significantly positively correlated with daily phosphorus intake but not with any components of metabolic syndrome $(p>0.05)$ (Table 3$)$.

Table 3. Correlation for BP, WC, Glucose, TG, HDL and daily phosphorus intake $(\mathrm{N}=893)$.

\begin{tabular}{|c|c|c|c|c|c|c|c|c|}
\hline & BPsys & BPdia & WC & Glucose & HDL & TG & $\begin{array}{c}\text { Phosphorus } \\
\text { Intake }\end{array}$ & $\begin{array}{l}\text { Calcium } \\
\text { Intake }\end{array}$ \\
\hline BPsys & 1 & & & & & & & \\
\hline BPdia & $0.448(<0.001) *$ & 1 & & & & & & \\
\hline WC & $0.482(<0.001) *$ & $0.209(<0.001) *$ & 1 & & & & & \\
\hline glucose & $0.129(<0.001) *$ & $0.035(0.340)$ & $0.153(<0.001) *$ & 1 & & & & \\
\hline HDL & $-0.169(<0.001) *$ & $-0.107(0.003)$ * & $-0.352(<0.001) *$ & $-0.063(0.082)$ & 1 & & & \\
\hline TG & $0.203(<0.001) *$ & $0.139(<0.001)^{*}$ & $0.325(<0.001) *$ & $0.167(<0.001)^{*}$ & $-0.361(<0.001) *$ & 1 & & \\
\hline $\begin{array}{c}\text { Phosphorus } \\
\text { intake }\end{array}$ & $0.103(0.004) *$ & $-0.005(0.891)$ & $0.115(0.001) *$ & $0.020(0.575)$ & $-0.113(0.002) *$ & $-0.020(0.579)$ & 1 & \\
\hline Calcium intake & $0.058(0.100)$ & $-0.004(0.907)$ & $0.049(0.163)$ & $0.029(0.425)$ & $-0.063(.079)$ & $-0.041(0.251)$ & $0.697(<0.001)^{*}$ & 1 \\
\hline
\end{tabular}

BPsys: Systolic Blood Pressure, BPdia: Diastolic Blood Pressure, WC: Waist circumference, HDL: High Density Lipoprotein, TG: Triglyceride. ${ }^{*} p<0.05$. 


\subsection{Predictors of Metabolic Syndrome}

A regression analysis was performed using systolic blood pressure, waist circumference, HDL cholesterol, and serum creatinine, which were significantly correlated with the components of metabolic syndrome and daily phosphorus intake, as the predictor variables. As serum creatinine increased by 1 , the risk of metabolic syndrome increased 16.452-fold (OR: 16.452, 95\% CI: 1.701-159.136, $p<0.05$ ). The relative risk of metabolic syndrome based on diastolic blood pressure, waist circumference, and HDL cholesterol was $0.983,0.982$, and 1.007 , respectively; these variables were not significant predictors of metabolic syndrome $(p>0.05)$ (Table 4$)$.

Table 4. Risk Factors for Metabolic Syndrome ( $\mathrm{N}=893)$.

\begin{tabular}{|c|c|c|c|c|c|c|c|c|}
\hline \multirow{2}{*}{ Category } & \multirow{2}{*}{ B } & \multirow{2}{*}{ S.E. } & \multirow{2}{*}{ Wald } & \multirow{2}{*}{ df } & \multirow{2}{*}{$p$} & \multirow{2}{*}{$\operatorname{Exp}(\mathrm{B})$} & \multicolumn{2}{|c|}{ 95\% C.I. } \\
\hline & & & & & & & Lower & Upper \\
\hline Systolic BP (mmHg) & -0.007 & 0.020 & 0.115 & 1 & 0.735 & 0.993 & 0.955 & 1.033 \\
\hline Waist circumference $(\mathrm{cm})$ & -0.018 & 0.021 & 0.735 & 1 & 0.391 & 0.982 & 0.943 & 1.023 \\
\hline HDL cholesterol (mg/dL) & 0.007 & 0.018 & 0.129 & 1 & 0.719 & 1.007 & 0.971 & 1.043 \\
\hline Serum creatinine $(\mathrm{mg} / \mathrm{dL})$ & 2.800 & 1.158 & 5.850 & 1 & $0.016^{*}$ & 16.452 & 1.701 & 159.136 \\
\hline Constant & -3.161 & 2.381 & 1.762 & 1 & 0.184 & 0.042 & & \\
\hline
\end{tabular}

HDL: High Density Lipoprotein, TG: Triglyceride. ${ }^{*} p<0.05$.

\section{Discussion}

The present descriptive survey study analyzed the 7th KNHANES VII-3 (2018) and the 8th KNHANES VII-1 (2019) to investigate the correlations between metabolic syndrome and mineral imbalance in adolescents.

The incidence of metabolic syndrome among the adolescents included in this study was $5.9 \%$ for males and $4.7 \%$ for females. This incidence was lower than the prevalence of metabolic syndrome (10.1\%) reported for adolescents aged 12-19 years in the 2001-2010 National Health and Nutrition Examination Survey in the United States [25], as well as that (6.3\%) reported for Asian countries [3].

In this study, the participants' calcium intake did not meet the recommended calcium intake; on the other hand, phosphorus intake met the recommended level. Also, only $2.9 \%$ of all participants had a calcium/phosphorus ratio of $1: 1$ (2.1\% of males, $3.7 \%$ of females). Most participants (43.9\%) had a calcium/phosphorus ratio of 1:2, and $8.6 \%$ of all participants had a ratio of 1:4, indicating a severe calcium/phosphorus imbalance among the participants. This result is closely associated with the dietary habits of adolescents. Soft drinks and sports drinks, commonly enjoyed by adolescents, contain up to 4.2 times and 48.5 times more phosphorus than calcium, respectively [26]. Of the 57,303 adolescents in the 15th Online Youth Health Behavior Survey (2019), 50.7\% consumed soft drinks at least three times per week [27], supporting the results of this study that high phosphorus intake ratio compares to calcium.

In the analysis of correlations between calcium and phosphorus intakes and the components of metabolic syndrome, no significant correlations were found between calcium intake and the components of metabolic syndrome. Phosphorus intake was significantly positively correlated with systolic blood pressure and waist circumference and significantly negatively correlated with HDL cholesterol. Phosphorus intake was also significantly positively correlated with calcium intake $(p<0.05)$. A previous study reported elevated phosphorus levels as a risk factor for cardiovascular disease in adults. A study analyzing the Third National Health and Nutrition Examination Survey (NHANES III) (1988-1994) reported that the joint effect of elevated phosphorus levels and hypertension increases the mortality due to cardiovascular disease [15]. In a study on adults aged 40-59 years in Asia, Europe, and the United States, phosphorus intake was directly proportional to systolic and diastolic blood pressure [28]. A similar result was obtained in this study in which phosphorus intake was positively correlated with systolic blood pressure, confirming that 
high phosphorus intake increases the risk of metabolic syndrome. A study analyzing data from 88,094 Americans aged $\geq 17$ years reported that the prevalence of obesity increased with serum phosphorus levels [29]. A study analyzing computed tomography (CT) results of 2509 healthy Korean adults found that the risk of coronary calcification increased with serum phosphorus levels [30], a finding that was consistent with the results of this study. Although the present study examined adolescents aged $12-18$ years, it is meaningful that similar results were observed between this study and others that examined adults or elderly subjects, since health problems during adolescence such as pediatric obesity have been traditionally considered to be risk factors of metabolic syndrome [3]. This is because these results indicate that similar risk factors are at play between adolescents and adults in cases of metabolic syndrome and that it is closely associated with long-term health problems.

A significant difference in serum creatinine levels was found according to the calcium/phosphorus ratio. Creatinine is a metabolite of creatinine in muscles or a waste product of proteins. It is an important indicator of renal function alongside BUN. The normal range of creatinine is $0.5-1.4 \mathrm{mg} / \mathrm{dL}$. Since creatinine is produced in muscles, it is found in higher levels among individuals with high muscle mass such as younger individuals than among the elderly and in higher levels among males than among females [31]. The serum creatinine levels in this study were within the normal range for both male and female participants $(0.77 \mathrm{mg} / \mathrm{dL}$ and $0.62 \mathrm{mg} / \mathrm{dL}$, respectively). However, a binomial logistic regression analysis revealed a 16-fold increase in the risk of metabolic syndrome for every $1 \mathrm{mg} / \mathrm{dL}$ increase in the serum creatinine level $(p<0.05)$. Although the exact mechanism by which serum creatinine levels increase the risk of metabolic syndrome is unclear, a previous study found that elevated creatinine levels increased six-fold the mortality of patients who had undergone heart surgery or had had heart disease [31]. A study following up on 7690 middle-aged men with no unusual conditions for an average of 14 years also reported that elevated serum creatinine levels are a risk factor of cardiovascular disease [32]. A Framingham Heart study analyzing serum creatinine levels of subjects without heart or renal disease found a correlation between hypertension, which is a component of metabolic syndrome, and BMI [33], and another study suggested serum creatinine as a predictor for the risk of metabolic syndrome [34]. In addition, the results of this study also showed that blood creatinine level is a factor that increases the risk of metabolic syndrome, which can predict the relationship between increased blood creatinine level and cardiovascular disease. The results of this study demonstrate that a continued imbalance between calcium and phosphorus intakes can potentially affect serum creatinine levels even in adolescents and act as a risk factor for metabolic syndrome, suggesting the need to monitor the intakes of these minerals in adolescents.

However, since the participants of this study were adolescents, who are a relatively healthy population group with a lower incidence of metabolic syndrome, it was difficult to accurately examine the effect of calcium intake, necessitating a future follow-up study. This study has limitations in that time-series analysis could not be done due to the cross-sectional descriptive design of the study, and the relationships between the risk of metabolic syndrome and factors such as the serum phosphorus or calcium level could not be inferred thoroughly. Also, there is a limit to calculating long-term intake. In addition, since the reference values of adolescents are very different among the various countries, interpretation of the results should be made with caution.

\section{Conclusions}

This is the first study to explore the relationship between calcium, phosphorus intake and the prevalence of metabolic syndrome among Korean adolescents using Korean national survey data. This study confirmed that the calcium and phosphorus intake imbalance of adolescents was serious, and in particular, excessive phosphorus intake was associated with the risk of metabolic syndrome. The results of this study suggest the necessity of education to emphasize balanced diet and to reduce the consumption of soft drinks and instant foods. In addition to that, existing metabolic syndrome prevention and manage- 
ment programs targeted at adults should expand their target population to adolescents to preemptively reduce the prevalence of metabolic syndrome starting with adolescence. This study is meaningful in that it determines the correlations between metabolic syndrome and calcium or phosphorus intakes in adolescents, who have not been the priority of metabolic syndrome prevention efforts. Continued research on the relationship between mineral intake and metabolic syndrome in adolescents is recommended as well as development of health promotion programs aimed at preventing metabolic syndrome among adolescents.

Author Contributions: Data collection: Y.P. and J.H.; data analysis: Y.P. and J.H.; manuscript writing: Y.P. and J.H. All authors have read and agreed to the published version of the manuscript.

Funding: This research was funded by Joongbu University Research \& Development Fund, in 2021 (No: 2021-1006-015).

Institutional Review Board Statement: This study was conducted after being reviewed for exemption by the Institutional Review Board (SMU-EX-2021-7-001).

Informed Consent Statement: Not applicable.

Data Availability Statement: Not applicable.

Conflicts of Interest: The authors declare no conflict of interest.

\section{References}

1. Expert Panel on Detection, Evaluation, and Treatment of High Blood Cholesterol in Adults. Executive summary of the third report of the National Cholesterol Education Program (NCEP) expert panel on detection, evaluation, and treatment of high blood cholesterol in adults (adult treatment panel III). JAMA 2001, 285, 2486-2497. [CrossRef]

2. Huh, J.-H.; Kang, D.-R.; Kim, J.-Y.; Koh, K.-K.; Korean Society of Cardiometabolic Syndrome. Metabolic Syndrome Fact Sheet in Korea. Cardiometab. Syndr. J. 2021, 1, 125-134. [CrossRef]

3. Bitew, Z.W.; Alemu, A.; Tenaw, Z.; Alebel, A.; Worku, T.; Ayele, E.G. Prevalence of Metabolic Syndrome among Children and Adolescents in High-Income Countries: A Systematic Review and Meta-Analysis of Observational Studies. BioMed Res. Int. 2021, 2021, 6661457. [CrossRef]

4. Korea Disease Control and Preventon Agency. Health Behavior and Chronic Disease Statistics 2016. Available online: https: //knhanes.kdca.go.kr/knhanes/sub04/sub04_04_01.do (accessed on 1 June 2021).

5. Park, E.S.; Kim, M.H.; Choi, M.K. Nutritional Assessment Focusing on Minerals of Ready-to-Cook Foods Sold in Korea. J. East Asian Soc. Diet Life 2019, 29, 501-510. [CrossRef]

6. Lee, J.; Ahn, R.; Kang, H.; Choi, S.; Hong, C.; Kim, J.-G. Factors Associated with the Concentrations of Urinary Creatinine in Korean Children and Adolescents. J. Environ. Health Sci. 2012, 38, 291-299. [CrossRef]

7. Grodner, M.; Roth, S.R. Nutritional Foundations and Clinical Applications, 6th ed.; Elsevier-Health Science: New York, NY, USA, 2016; pp. 150-200.

8. Shaker, J.L.; Deftos, L. Calcium and phosphate homeostasis. Blood Purif. 2009, 27, 387-394. [CrossRef]

9. Ross, A.C.; Caballero, B.; Cousins, R.J.; Tucker, K.L.; Ziegler, T.R. Modern Nutrition in Health and Disease; Lippincott Williams \& Wilkins: Philadelphia, PA, USA, 2012.

10. Kwon, O. 2020 Dietary Reference Intakes for Koreans (KDRIs): Minerals; Ministry of Health and Welfare: Sejong, Korea, 2020.

11. Kim, H.; Lee, U.; Kim, S.; Cha, Y. Evaluation of dietary habits according to breakfast consumption in Korean adolescents: Based on the 6th Korea National Health and Nutrition Examination Survey, 2013 2015. J. Nutr. Health 2019, 52, 217-226. [CrossRef]

12. Bae, Y.; Yeon, J. A Study on nutritional status and dietary quality according to carbonated drink consumption in male adolescents: Based on 2007 2009 Korean National Health and Nutrition Examination Survey. J. Nutr. Health 2015, 48, 488-495. [CrossRef]

13. Ito, S.; Ishida, H.; Uenishi, K.; Murakami, K.; Sasaki, S. The relationship between habitual dietary phosphorus and calcium intake, and bone mineral density in young Japanese women: A cross-sectional study. Asia Pac. J. Clin. Nutr. 2011, 20, 411-417. [CrossRef]

14. Ketteler, M.; Wolf, M.; Hahn, K.; Ritz, E. Phosphate: A novel cardiovascular risk factor. Eur. Heart J. 2021, 34, 1099-1101. [CrossRef]

15. Vart, P.; Nigatu, Y.; Jaglan, A.; van Zon, S.; Shafique, K. Joint effect of hypertension and elevated serum phosphorus on the risk of mortality in National health and Nutrition Examination Survey-III. J. Am. Heart Assoc. 2015, 4, e001706. [CrossRef] [PubMed]

16. Choi, Y.B.; Kim, J.H.; Lee, M.J.; Choi, S.; Kim, H.J. The relationship between serum phosphorous level and arteriovenous fistula dysfunction in maintenance hemodialysis patients. Korean J. Med. 2020, 95, 36-42. [CrossRef]

17. Chrysant, S.G.; Chrysant, G.S. Controversy regarding the association of high calcium intake and increased risk for cardiovascular disease. Wiley Online Libr. 2014, 16, 545-550. [CrossRef] [PubMed]

18. World Health Organization. Diet, Nutrition and the Prevention of Chronic Diseases: Report of a Joint FAO/WHO Expert Consultation. 2003. Available online: https://apps.who.int/nutrition/publications/obesity/WHO_TRS_916/en/ (accessed on 1 June 2021). 
19. Katz, M. Vitamins and minerals deficiencies: Their role in chronic non communicable diseases. Ann. Nutr. Metab. 2017, 71, 1333.

20. de Magalhães Cunha, C.; Costa, P.R.; de Oliveira, L.P.; de O. Queiroz, V.A.; Pitangueira, J.C.; Oliveira, A.M. Dietary patterns and cardiometabolic risk factors among adolescents: Systematic review and meta-analysis. Br. J. Nutr. 2018, 119, 859-879. [CrossRef] [PubMed]

21. Kelishadi, R.; Heshmat, R.; Mansourian, M.; Motlagh, M.E.; Ziaodini, H.; Taheri, M.; Ahadi, Z.; Aminaee, T.; Goodarzi, A.; Mansourian, M.; et al. Association of dietary patterns with continuous metabolic syndrome in children and adolescents; a nationwide propensity score-matched analysis: The CASPIAN-V study. Diabetol. Metab. Syndr. 2018, 10, 52. [CrossRef]

22. Lee, Y.; Shin, C.; Lim, J. Measures against pediatric metabolic syndrome. J. Korean Med. Assoc. 2010, 53, 392-406. [CrossRef]

23. Oh, M.J.; Lee, M.J.; Lee, K.H.; Park, M.S.; Ko, J.A. Association of proteinuria with metabolic syndrome in Korean adults. Korean J. Fam. Med. 2010, 31, 437-443. [CrossRef]

24. Kim, B. Quick Reference Guideline 2020; Korean Society for the Study of Obesity: Seoul, Korea, 2020.

25. Aguilar, M.; Bhuket, T.; Torres, S.; Liu, B.; Wong, R.J. Prevalence of the metabolic syndrome in the United States, 2003-2012. JAMA 2015, 313, 1973-1974. [CrossRef]

26. Kim, S.; Moon, H.; Park, J.; Yang, H.; Yi, Y.; Han, E.; Lee, Y.C.; Shin, G.Y.; Kim, J.H.; Chae, Y.Z. The content of macrominerals in beverages, liquid teas, and liquid coffees. J. Korean Soc. Food Sci. Nutr. 2012, 41, 1134-1143. [CrossRef]

27. Park, S.K.; Lee, J.H. Factors influencing the consumption of convenience foods among Korean adolescents: Analysis of data from the 15th (2019) Korea Youth Risk Behavior Web-based Survey. J. Nutr. Health 2020, 53, 255-270. [CrossRef]

28. Elliott, P.; Kesteloot, H.; Appel, L.J.; Dyer, A.R.; Ueshima, H.; Chan, Q.; Brown, I.J.; Zhao, L.; Stamler, J. Dietary phosphorus and blood pressure: International study of macro-and micro-nutrients and blood pressure. Hypertension 2008, 51, 669-675. [CrossRef] [PubMed]

29. Sim, J.; Smith, N.; Chung, J.; Kalantar-Zadeh, K. Evaluation of serum phosphorus levels and obesity. Kidney Res. Clin. Pract. 2012, 31, A74. [CrossRef]

30. Park, K.S.; Park, J.; Choi, S.H.; Ann, S.H.; Singh, G.B.; Shin, E.-S.; Lee, J.S.; Chung, H.C. Serum phosphorus concentration and coronary artery calcification in subjects without renal dysfunction. PLoS ONE. 2016, 11, e0151007. [CrossRef]

31. Praught, M.L.; Shlipak, M.G. Are small changes in serum creatinine an important risk factor? Curr. Opin. Nephrol. Hypertens. 2005, 14, 265-270. [CrossRef] [PubMed]

32. Wannamethee, S.G.; Shaper, A.G.; Perry, I.J. Serum creatinine concentration and risk of cardiovascular disease: A possible marker for increased risk of stroke. Stroke 1997, 28, 557-563. [CrossRef]

33. Culleton, B.F.; Larson, M.G.; Evans, J.C.; Wilson, P.W.F.; Barrett, B.J.; Parfrey, P.S.; Levy, D. Prevalence and correlates of elevated serum creatinine levels: The Framingham Heart Study. Arch. Intern. Med. 1999, 159, 1785-1790. [CrossRef]

34. Shin, S.R.; Han, A.L. Relationship between metabolic syndrome and uric acid to creatinine ratio in Korean adults: Korea National Health and Nutrition Examination Survey 2016. Korean J. Health Promot. 2018, 18, 113-118. [CrossRef] 